\title{
Editorial
}

\section{Health promoting policies: strong, weak, ..., and sometimes harmful?}

The notion that the state must develop policies to protect and promote the health of its citizens is a very old one. In the course of the last hundred years the notion of what the state needs to do in that respect has expanded very greatly; from various forms of eradication of the undesirable, or attempts to prevent its occurrence, nations have moved increasingly to policies which are intended positively to promote and advance good health. In health related areas ranging from food labelling and labour laws to environmental control the modern state is taking more upon itself than ever before. That development has not gone unchallenged; while much of the criticism of the process has related to evidence that the state is not doing enough - or is doing it in a costly and inefficient manner there is also from time to time an accusation that government measures to advance health, however well-intentioned, may actually do positive harm.

Some of such charges can be dismissed without much difficulty. In the field of drug regulation, for example, it has been argued that excessively restrictive laws discourage creative research, thus depriving the population of useful drugs or causing such drugs to reach the population so late that proper care is impaired. In one classic diatribe in the seventies, it was alleged that “... eleven years of delay in introducing beta-blockers into the United States, for indications other than arrhythmias, killed a quarter of a million Americans" [1]. That in turn led another writer to castigate broadly “... the mass murder activities of regulatory authorities" [2]. Such expressions of exasperation, often on the part of an aggrieved health industry do not usually prove, when one examines them, to mean very much. All the same, one does need to look seriously at the broad question whether policies developed by governments with the intention of advancing the health of the population actually can affect it adversely. Can they?

\section{The case of the Soviet Union: 1917-1989}

The history of certain health policies in the former Soviet Union provides a very concrete area which lends itself for study. In the young Union of the early nineteen twenties, ideals were high and the field for action was wide open. In every field of activity society was restructured, as ruthlessly as necessary, to create what was envisaged as a brave new world. Whatever Moscow believed needed to be done, could be done; a series of five-year plans ensured that what was envisaged would be achieved, not merely for a short period, but far into the future. And since one of the fundamental needs was to feed 
a large, diverse and growing population reliably and well, a planned and orderly development of the food supply became a major component of those plans; horticulture, agriculture, food manufacturing and distribution were all taken as matters which must be systematically and scientifically tackled in the interests of building a strong and healthy nation.

In retrospect what that meant was that the state of the nutrition and food production science in the early nineteen twenties was taken as the basis for firm, long-term policies which became engraved, as it were, in stone; they dictated the goals set for the agricultural and other sectors, and therefore also the infrastructure on which these were to be built, the facilities with which they were provided, and the training given to their people. And so these things remained, little influenced by changes in scientific thinking and knowledge in the world outside, for nearly seventy years, until, at the end of the eighties, the entire Soviet Union collapsed.

With the disintegration of the Union, a fascinating process of study began. Here was a society which to an important extent had chosen to go its own way for three generations. Here, for the first time, data were slowly becoming accessible on that society, ready for analysis and for international comparison. What had the results of that vast social experiment been?

I shall limit myself here to certain issues of public health, and indeed more narrowly to the question of the food chain, the feeding of the population, and the ultimate effect upon its nutritional wellbeing.

\section{The public health picture}

In any society, the quality of the overall dietary pattern is likely to be reflected in a number of aspects of health. In particular, figures relating to premature cardiovascular mortality can be relevant. Once reasonably reliable figures on these matters in the former Soviet Republics became available for study it was more than evident that something was gravely wrong.

Figure 1 shows the annual figures on deaths from ischaemic heart disease as they became available, including some retrospective figures covering the final years of the USSR's existence*. The upper three curves represent the situation in Russia, Ukraine and Kazakhstan, respectively; the deaths per hundred thousand population in 1981 for these three Soviet republics were 93, 92 and 88, respectively. By contrast, as the lower two curves show, the average annual mortality from this cause in 1981 in the countries of the European Union was only 46, while in the five Nordic countries (Norway, Sweden, Finland, Iceland and Denmark), three of which are geographically very close to the former Soviet Union, mortality in 1981 was rather higher but still only 69 per 100,000 with a downwards trend. These differences between east and west are highly significant.

Figure 2 shows an even greater contrast with western countries where cerebrovascular disease is concerned. Annual mortality data for the three ex-Soviet Republics ranged between 44 and 56 in 1981; the EU average figure was only 18 and the Nordic countries showed an average mortality as low as 15 per 100,000, in both cases with a well-established and continuing decline.

These are only examples, but the astonishing picture which they present comes to the fore to a greater or lesser degree if one looks at other measures of circulatory mortality, at figures broken down by sex or age, and at other countries within or beyond the borders of the former Soviet Union. For one reason or another, the mortality figures in this medical field were some two-and-a half times higher

\footnotetext{
${ }^{*}$ Figures 1 and 2 are based on data supplied to the World Health Organization by the countries concerned, and incorporated into the Organization's Nutrition Data Base.
} 


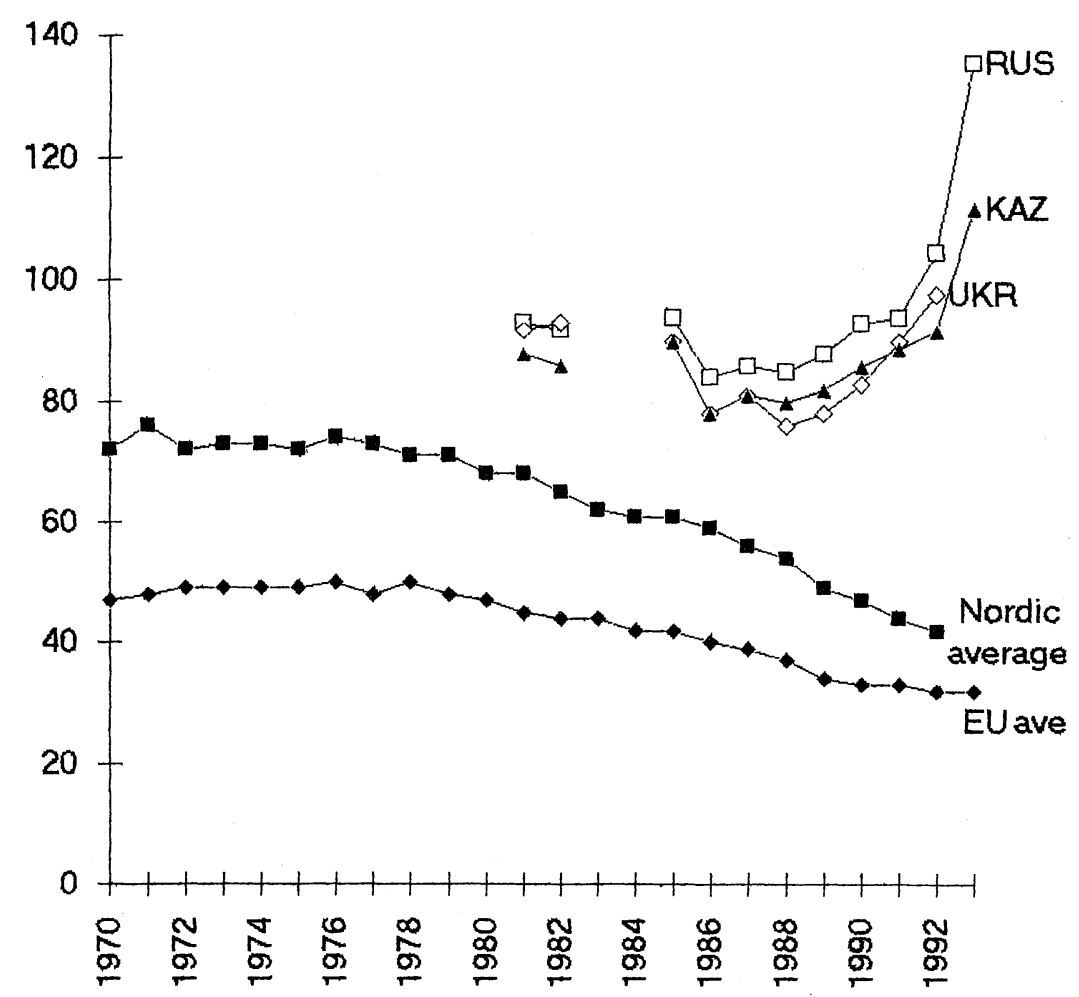

Fig. 1. Standardized death rates per 100,000 population for ischaemic heart disease in persons aged 0-64 years.

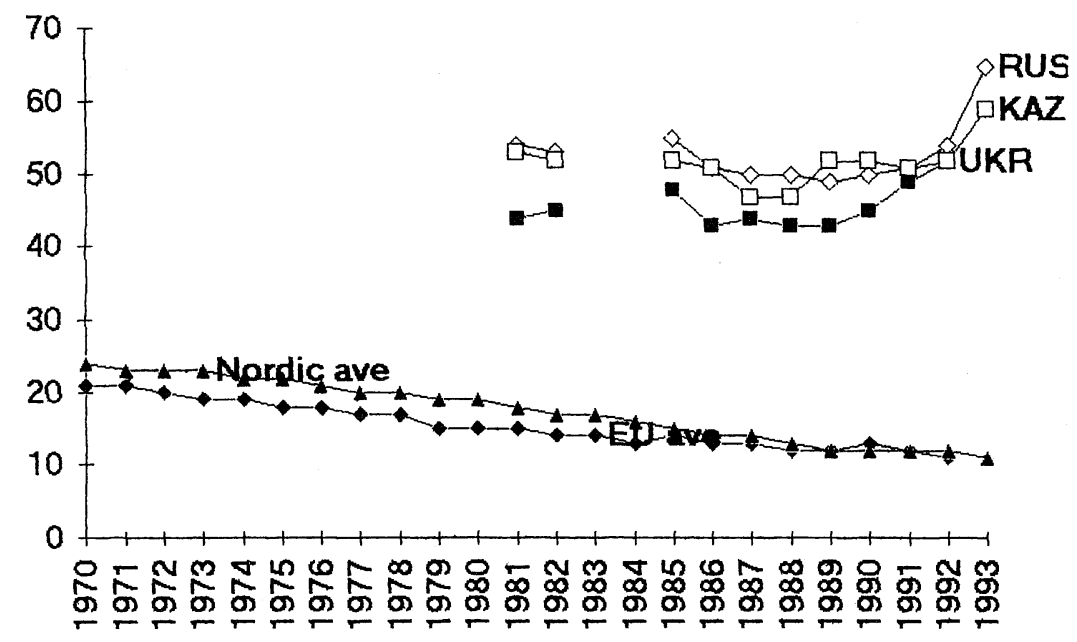

Fig. 2. Standardized death rates per 100,000 population for cerebrovascular disease in persons aged 0-64 years.

than in western countries, even in countries lying in close proximity to the former USSR. Clearly, one hypothesis must be that the prevailing dietary pattern was to a large extent responsible.

One should add that these few examples relating to cardiovascular disease could be supplemented by others, related to other fields of morbidity and mortality in which dietary patterns are known to play a causative or catalytic role. 


\section{The nutrition picture}

It is clear, from what one knows of the definition of food supply policies in the early years of the former Soviet Union, that two factors were dominant in political thinking and in planning. One was the evident need to provide sufficient food overall for the population, which in the past had suffered much from food insecurity. The other, dictated by the nutrition beliefs of the pre-World-War-II period, was to provide sufficient animal protein. Agriculture and animal husbandry were attuned to that latter goal; there was a heavy emphasis on the production of meat, and World Bank figures show that over half of the total grain production was directed to the feeding of animals for meat production [3]. Far less well developed was the provision of fresh vegetables and fruit, especially to the cities because of a failure to provide rapid cooled transportation to ensure their arrival in good condition. Perishable commodities are obviously less easy to manage within a tightly controlled command economy system.

The consequences are clear from the best figures available for the food supply in the former Soviet Union. Whereas in 1992 it could be calculated that in the countries of the European Union the proportion of total energy available from protein generally ranged between $10-12 \%$ the corresponding figure for Russia was 14.3 - a difference which in food supply terms is highly significant. These figures are supplemented by reliable impressions from observers; it is clear that in the late eighties the supply of fresh fruit and vegetables to urban populations in the former Soviet Union left everything to be desired; that the meat available had a high fat content, and that choice and variety in the food supply was - as it had been for many years - extremely limited. One might add that the role of nutrition education of the public was also scarcely developed; this process which in the west has over a long period led to a progressively wiser choice of foodstuffs has hardly gained any momentum further East; choice being so limited, it would indeed have been almost pointless to develop consumer education in this area. It was not on the agenda to link 'choice' of food with health - the emphasis had been on providing enough food for everybody, in which one had admirably succeeded. The science of nutrition had not been among those selected for contact with the West (in contrast to, for example, heart disease, where the Kremlin gerontocracy could not afford to take any chances, and saw to it that contacts with the west were frequent and unimpeded).

\section{The post-Soviet era}

From the end of the eighties onwards, the old course of the former Soviet Union no longer dictated policies; but it would be fair to say that no other and better policy miraculously emerged to take its place. The breakdown of services and supplies and the derangement of the economy led to an aggravation of social problems which has still not found a solution; the problems included those in the production and supply of foods. They are reflected in many health measures including the few cited in Figs. 1 and 2 in this Editorial; far from emulating the decline in premature mortality which has long been in progress in the West, there has been a most serious worsening of the situation. In 1992 , to quote only a single figure, annual premature mortality (before the age of 65) from ischaemic heart disease in Russia was reported to have attained 104.6 per 100,000, compared with a level of 32.0 in the European Union; the Russian situation continued to worsen rapidly, mortality attaining 135.9 in 1993, while the mortality figures in the west continued their long decline and are currently well below 40 per 100,000. This is not the place to discuss the current scene in the former Soviet countries which reflects a breakdown of policy rather than incorrect policies, but it must be a matter of grave concern. 


\section{Food and nutrition policies - a proven link to poor health?}

It is entirely clear that factors other than food intake could and did influence the figures for cardiovascular mortality in the latter years of the former Soviet Union. Cigarette smoking was, for example, widespread and has become progressively more so; alcohol consumption is heavy. Poverty, despite everything, has become and has remained a widespread problem, especially in the cities. Nevertheless, there is so much evidence for a role of incorrect nutrition on the state of health that it cannot be ignored. In Russian food composition tables, there are only two categories of meat - 'prime' and 'second', the former containing a much higher level of fat; fat meat is expensive, yet popular and in great demand; no better illustration could be given of the failure to teach the population modern concepts of sound nutrition.

\section{The lessons}

The single massive example discussed here - and there are many more - provides convincing evidence that ill-founded and rigid government policies albeit originally designed to advance health, may indeed eventually do more harm than good. Like other health sciences, the science of nutrition does make errors but as a rule it goes on, through a process of debate, challenge and experimentation, to correct them. It is clear that a health policy based on any current view of science must remain sufficiently flexible to adapt to change and to correct its course as necessary.

The development of complex sciences is and should be an international affair. Nutrition scientists in the West in the 1960's realized that although the metabolism of amino acids making up proteins is theoretically limited if one essential amino acid is in short supply, in real life this happens only under extreme circumstances. It was realized that in practical policy terms 'with enough calories available, the protein takes care of itself'. This in turn led to a downward adjustment of the recommended dietary allowances for protein [4] in 1971. Soviet scientists were hardly represented in the international expert meetings on nutrition where standards were discussed and set in this post-war period. This is perhaps not surprising, given the introspective and static state of nutrition science in the country at the time.

Policy making is the art of the possible. What is possible depends on the situation, which therefore must be objectively assessed. There was scant attention to the development of the dietary patterns in the Soviet era. Perhaps the leadership intuitively reckoned that sleeping dogs were best left lying, and that this was a potentially very mean dog. The dietary surveys that were undertaken were few, unrepresentative, and poorly designed, and kept under close wraps. This made adjustments impossible, and stopped any discussion.

Policy making requires continuous assessment of the reality against the policy objectives, and there is nothing static about the forces influencing public health. Perhaps we have largely learnt the lesson in the West. At the moment of writing, the debate on a current issue in food supply - the use of genetically modified foods - is going precisely through the process of debate and revision which is necessary to provide the basis for future policies. Happily, the policy debate is open. While the United States and Canada in 1995-96 approved a form of maize which had been genetically engineered to resist a major pest (the European corn borer) a majority of European states provisionally objected to its entry into the European Union, because of possible risks to human subjects [5]. The debate will no doubt continue and global policies will evolve in line with the growth of scientific knowledge and practical experience. That is precisely the way that things should happen. At the same time, in this as in every other field of health policy, one will need to jealously ensure a continuing feedback in terms 
of monitoring of the dietary pattern and its related health variables to ensure that objectives which have been set are indeed relevant to the situation, and that the results of actions taken are at the very least not doing more harm than good.

\section{Elisabet Helsing*}

\section{References}

[1] B.G. James, The Future of the Multinational Pharmaceutical Industry to 1990, ABP Ltd., London, 1977.

[2] B. Cromie, Present problems: the effects of British regulations, in: Medicines for the Year 2000, Office of Health Economics, London, 1979.

[3] World Bank, Food and agricultural policy reforms in the former USSR, Studies of Economies in Transformation, Paper No. 1 IBRD/World Bank, Washington, DC, 1992.

[4] FAO/WHO Energy and Protein Requirements. Report of a Joint FAO/lWHO Ad Hoc Expert Committee, Rome 22 March-2 April 1971, WHO Technical Report Series No. 522, Geneva, 1973.

[5] A. Maitland, Crop of fears over maize, Financial Times, August 9th, 1996, 15.

${ }^{*}$ Elisabet Helsing, Ph.D., Oslo, is a nutrition physiologist and was from 1984 to 1996 head of the Nutrition Programme of the World Health Organization (Europe). 